\title{
Online web-based sun-protective behaviors
}

This article was published in the following Dove Press journal:

Psychology Research and Behavior Management

5 March 2014

Number of times this article has been viewed

\section{Nicola Luigi Bragazzi ${ }^{1,2}$}

'School of Public Health, Department of Health Sciences (DISSAL),

University of Genoa, Via Antonio

Pastore,Genoa, Italy; ${ }^{2}$ DINOGMI,

Department of Neuroscience,

Rehabilitation, Ophthalmology,

Genetics, Maternal and Child Health, Section of Psychiatry, University of

Genoa, Genoa, Italy
Correspondence: Nicola Luigi Bragazzi

School of Public Health, Department

of Health Sciences (DISSAL),

University of Genoa, Via Antonio

Pastore I, I6132 Genoa, Italy

Tel +39 I 03537664

Fax +39 I 03537669

Email robertobragazzi@gmail.com

\section{Dear editor}

I read with great interest the recently published article by Diao and Lee ${ }^{1}$ concerning the sun-protective behaviors in populations at high risk for skin cancer, with a special emphasis on melanoma. Even though the manuscript was not intended as a systematic review, it provides primary care practitioners with useful information and detailed recommendations.

However it should be stressed that dermatology, as well as the other medical branches and specialties, has faced many progresses in recent years, thanks to the technological advancements (the so-called "teledermatology") ${ }^{2}$ and the achievements in the field of molecular and systems biology. ${ }^{3}$

The relationship between the patient and physician has changed, shifting from paternalism to a new model of shared medicine: the so-called P6 model (where the six Ps stand for personalized, preventive, predictive, participatory, psycho-cognitive, and public). ${ }^{4,5}$ New emerging concepts such as those of empowerment, self-efficacy and patient centeredness are now shaping the everyday clinical practice, in which the patient tries to be more culturally competent about his/her own disease, collecting information on the Internet and sharing his/her own experience. Electronic interactive applications and websites devoted to teaching the importance of the behavior of skin self-examination and self-screening are becoming widespread and quite common. ${ }^{6}$ More and more dermatological patients are exploiting the Internet and are, overall, satisfied with their online experience. The Internet can offer highly individualized health communication messages enabled by computer tailored technologies. ${ }^{7}$

However, in some cases, information available on the Internet is not always of high quality, complete, accurate, and reliable. The existence of a digital gap or divide could be a further obstacle in open access to these websites and in the adoption of proper preventive and protective behaviors. ${ }^{8}$

General practitioners and dermatologists should be aware of this phenomenon, investigating the attitudes of their patients to surf the web and to provide them with authoritative and reputed information.

In conclusion, a new array of sun-protective behaviors is emerging, termed as "public skin health", and understanding the drivers and the psychological variables of accessing online resources and adopting web-based sun-protective activities, in order to implement them and properly guiding the patients, is of extreme clinical interest. ${ }^{9-11}$ 


\section{Disclosure}

The author reports no conflicts of interest in this communication.

\section{References}

1. Diao DY, Lee TK. Sun-protective behaviors in populations at high risk for skin cancer. Psychol Res Behav Manag. 2013;20:7:9-18.

2. Fabbrocini G, De Vita V, Pastore F, et al. Teledermatology: from prevention to diagnosis of nonmelanoma and melanoma skin cancer. Int $J$ Telemed Appl. 2011;(2011):125762.

3. Hwa C, Bauer EA, Cohen DE. Skin biology. Dermatol Ther. Sep-Oct 2011; 24(5):464-470. J Cancer Educ. January 4, 2014. [Epub ahead of print.]

4. Bragazzi NL. From P0 to P6 medicine, a model of highly participatory, narrative, interactive, and "augmented" medicine: some considerations on Salvatore Iaconesi's clinical story. Patient Prefer Adherence. 2013;24;7: 353-359.

5. Bragazzi NL. Children, adolescents, and young adults participatory medicine: involving them in the health care process as a strategy for facing the infertility issue. Am J Bioeth. 2013;13(3):43-44.
6. Loescher LJ, Hibler E, Hiscox H, Quale L, Harris R. An Internetdelivered video intervention for skin self-examination by patients with melanoma. Arch Dermatol. 2010;146(8):922-923.

7. de Vries H, Logister M, Krekels G, Klaasse F, Servranckx V, van Osch L. Internet based computer tailored feedback on sunscreen use. $J$ Med Internet Res. 2012;30;14(2): 48.

8. Bichakjian CK, SchwartzJL, Wang TS, Hall JM, JohnsonTM, Biermann JS. Melanoma information on the Internet: often incomplete - a public health opportunity? J Clin Oncol. 2002;1;20(1):134-141.

9. Haluza D, Cervinka R. Perceived relevance of educative information on public (skin) health: a cross-sectional questionnaire survey. J Prev Med Public Health. 2013;46(2):82-88.

10. Marble N, Loescher LJ, Lim KH, Hiscox H. Use of technology for educating melanoma patients. J Cancer Educ. 2010;25(3):445-450.

11. Barysch MJ, Cozzio A, Kolm I, et al. Internet based health promotion campaign against skin cancer - Results of http://www.skincheck.ch in Switzerland. Eur J Dermatol. 2010;20(1):109-114. 


\section{Authors' reply}

\section{Diana Y Diao' \\ Tim K Lee ${ }^{1,2}$}

'Department of Dermatology and Skin Science, University of British Columbia, Vancouver, British Columbia, Canada; ${ }^{2}$ Cancer Control Research Program, BC Cancer Agency, Vancouver, British Columbia, Canada

Correspondence: Tim K Lee

Cancer Control Research Program, BC Cancer Agency, 675 West I0th Avenue, Vancouver, British Columbia, Canada V5Z IL3

Email tlee@bccrc.ca

\section{Dear editor}

We enjoyed reading the comments from Dr Bragazzi regarding our article. Dr Bragazzi points to the technological advancements and its growing role in medicine, and cites examples of new electronic interactive applications and websites used in patient education. We read these examples provided with great interest, and found them informative. Although acquiring medical knowledge from mass media is not new, we agree wholeheartedly that technology is playing a progressively larger role in medicine, and hope that it will continue to do so. At the same time, the studies cited by Dr Bragazzi reiterated the need for continued research into education and behavioral changes in high-risk populations for skin cancer. For example, Dr Bragazzi cites a study where video intervention in melanoma patients showed $37 \%$ of patients did not view the video despite email reminders to access this tool, and only 12 patients (out of 120 patients in this study) reported increased self-skin examinations in the 3 months after intervention. ${ }^{1}$ This study even recruited patients with self-reported good Internet and email proficiency, which is not always the case in the general high-risk population for skin cancer. Another study Dr Bragazzi cited, assessing the use of technology for educating melanoma patients, acknowledged that technology may provide an additional role, but all the recruited patients have received comprehensive in-person education in the Cutaneous Oncology Program; and patients may be more satisfied with one-on-one teaching with health care provider if there is adequate time for the encounter. ${ }^{2}$

Although technological applications have provided avenues and opportunities in dermatology (eg, teledermatology, various iPhone apps, interactive web-based tools, etc), uptake in the high-risk population related to preventative behavior should be evaluated further in order to optimize their influence on behavior. We agree that patients are taking on more active roles in directing their health care with physicians, and thus even more research is needed to understand the complex factors contributing to the existing low compliance rates. Health care professionals, along with the use of applications in technology with the appropriate patients, along with mass media and educators, should form part of a multidisciplinary approach in addressing the gap in behavioral change in high-risk groups.

\section{Disclosure}

The author reports no conflicts of interest in this communication.

\section{References}

1. Loescher LJ, Hibler E, Hiscox H, Quale L, Harris R. An Internetdelivered video intervention for skin self-examination by patients with melanoma. Arch Dermatol. 2010;146(8):922-923.

2. Marble N, Loescher LJ, Lim KH, Hiscox H. Use of technology for educating melanoma patients. J Cancer Educ. 2010;25(3):445-450.
Psychology Research and Behavior Management

\section{Publish your work in this journal}

Psychology Research and Behavior Management is an international, peerreviewed, open access journal focusing on the science of psychology and its application in behavior management to develop improved outcomes in the clinical, educational, sports and business arenas. Specific topics covered include: Neuroscience, memory \& decision making; Behavior

\section{Dovepress}

modification \& management; Clinical applications; Business \& sports performance management; Social and developmental studies; Animal studies. The manuscript management system is completely online and includes a quick and fair peer-review system. Visit http://www.dovepress. com/testimonials.php to read real quotes from published authors. 